\title{
SAÚDE MENTAL E TRABALHO FEMININO: IMAGENS E REPRESENTAÇÕES DE ENFERMEIRAS
}

\author{
Josicelia Dumêt Fernandes ${ }^{1}$ \\ Silvia Lúcia Ferreira ${ }^{2}$ \\ Aurenice Karine Albergaria ${ }^{3}$ \\ Flávia Matos da Conceição ${ }^{3}$
}

Fernandes JD, Ferreira SL, Albergaria AK, Conceição FM. Saúde mental e trabalho feminino: imagens e representações de enfermeiras. Rev Latino-am Enfermagem 2002 março-abril; 10(2):199-206.

Esta investigação avança na perspectiva da construção de um conhecimento sobre a relação saúde mental e trabalho na enfermagem. Consiste num estudo descritivo, com abordagem qualitativa, tendo, como eixo condutor, a Teoria das Representações Sociais e como suporte complementar, os estudos da Psicopatologia e Psicodinâmica do Trabalho. A análise indica que as representações das enfermeiras acerca da relação saúde mental e trabalho na enfermagem trazem a marca do individual e do coletivo organizacional, visualizando essas profissionais como produto e produtoras de sua história pessoal e de sua saúde mental no ambiente de trabalho, compreendendo-as como manifestação da totalidade social.

DESCRITORES: saúde mental, trabalho feminino, enfermagem

\section{MENTAL HEALTH AND WOMAN WORK: NURSES IMAGES AND REPRESENTATIONS}

This investigation advances on the perspective of the construction of knowledge on the relation between mental health and nursing work. It is a descriptive study based on a qualitative approach and on the Social Representations Theory as well as studies on Psychopathology and Work Psychodynamics. The analysis indicated that nurses representations on the relation between mental health and nursing work are influenced by the individual and collective-organizational levels, showing these professionals as a product and producers of their personal history and of the mental health regarding the work environment, understanding them as a manifestation of the social totality.

DESCRIPTORS: mental health, woman work, nursing

\section{SALUD MENTAL Y TRABAJO FEMENINO: IMÁGENES Y REPRESENTACIONES DE ENFERMERAS}

Esta investigación avanza en la perspectiva de la construcción de un conocimiento acerca de la relación salud mental y trabajo en enfermería. Es un estudio descriptivo, con una perspectiva cualitativa, teniendo como eje conductor la Teoría de las Representaciones Sociales y, como soporte complementar, los estudios de la psicopatología y psicodinámica del trabajo. El análisis indica que las representaciones de las enfermeras acerca de la relación salud mental y trabajo en la enfermería traen la marca de lo individual y de lo colectivo organizacional, visualizando esas profesionales como producto y productoras de su historia personal y de su salud mental en el ambiente de trabajo, comprendiéndolas como manifestación de la totalidad social.

DESCRIPTORES: salud mental, trabajo femenino, enfermería

\footnotetext{
${ }_{1}^{1}$ Professor Doutor, Pesquisador do Grupo de Estudos e Pesquisas em Saúde Mental (GESAM), e-mail: dumet@ufba.br; ${ }^{2}$ Professor Doutor, Pesquisador do Núcleo de Estudos Interdisciplinares sobre a Mulher (NEIM) e do Grupo de Estudos sobre Saúde da Mulher (GEM), e-mail: slferreira@ufba.br. Escola de Enfermagem da Universidade Federal da Bahia; ${ }^{3}$ Estudante de Enfermagem, Bolsista de Iniciação Científica
} 


\section{SITUANDO A PESQUISA}

A presente investigação surge na perspectiva da construção de um conhecimento sobre a relação entre saúde mental e trabalho feminino, através das imagens e representações de enfermeiras, categoria majoritariamente constituída por mulheres, cujo objeto, o cuidado, caracteriza-se como feminino. Essa especificidade atribui às enfermeiras e ao seu trabalho, características especiais: 0 cuidado, enquanto extensão do trabalho doméstico (invisível, subjetivo e socialmente desvalorizado), é exercido majoritariamente por mulheres, em um contexto onde a cura, através do diagnóstico e tratamento (visível, objetivo, e socialmente valorizado), é, ainda, majoritariamente, exercida por homens. Isso, contudo, não desconsidera as transformações que o mundo do trabalho hospitalar tem incorporado nos últimos tempos, com o advento dos novos equipamentos e tecnologias, uma vez que o cuidado de enfermagem é, também, mediado por essas transformações.

Partindo desse entendimento, este estudo busca, nas imagens e representações elaboradas por um grupo de enfermeiras, os significados e vivências do cotidiano do seu trabalho relativos à sua saúde mental, procurando apreender os processos e mecanismos que as direcionam ao "sofrimento criativo" " "sofrimento patogênico"(1). O sofrimento é considerado como o espaço de luta entre o "bemestar" e a doença mental ou a loucura. Em sua luta contra o sofrimento, o sujeito elabora soluções que são favoráveis tanto ao trabalho como à sua saúde, conduzindo-se ao "sofrimento criativo". Quando essas soluções são desfavoráveis à organização e à saúde do sujeito, instala-se o "sofrimento patogênico"(1).

Nessa perspectiva, estão definidos, para este estudo, os seguintes objetivos: conhecer como a enfermeira representa seu trabalho e a relação desse trabalho com a sua saúde mental; identificar, através das representações das enfermeiras, as estratégias construídas por elas no enfrentamento do sofrimento no seu trabalho e os fatores que têm relação na determinação do sofrimento criativo e sofrimento patogênico.

Para 0 alcance desses objetivos, esta investigação foi construída em torno do entendimento de que os sentimentos de prazer e sofrimento no trabalho da enfermagem, não existem enquanto entidades absolutas, isoladas e independentes de sua forma de expressão e manifestação nas enfermeiras, mas como entrelaçados às experiências de cada enfermeira, nas suas experiências e vivências de ordem pessoal e profissional; do entendimento da relação trabalho/ prazer/sofrimento como processo histórico onde o psicológico, o social e o organizacional entrelaçam-se, interconstituindo-se; do entendimento de que as enfermeiras são sujeitos do processo de construção do conhecimento sobre o sofrimento criativo e o sofrimento patogênico no seu trabalho; do entendimento desse processo como contextualizado, resultante das condições em que surge e circula, além de norteador das práticas e das relações das enfermeiras com seu objeto de trabalho.

\section{A TRAJETÓRIA DO ESTUDO}

Este é um estudo de natureza descritiva, com abordagem qualitativa, que busca as relações entre organização do trabalho na enfermagem e a saúde mental de suas agentes, identificando fatores que, na percepção dessas pessoas, têm relação na determinação do sofrimento criativo e do sofrimento patogênico. Prioriza o "pensar" e o "sentir" das profissionais de enfermagem, através de suas falas, suas expressões, como fontes de informação para apreensão das estratégias elaboradas por elas para enfrentar o cotidiano do seu trabalho. Busca desvendar o discurso enquanto uma estrutura de representação que conduz à subjetividade e informa sobre as características organizacionais do trabalho na enfermagem, bem como dos processos de enfrentamentos postos em prática pelas enfermeiras. Possibilita, enfim, a compreensão de como as representações sobre saúde mental e trabalho orientam as enfermeiras no enfrentamento do sofrimento no trabalho.

A análise, tendo a subjetividade como instrumento de conhecimento, utiliza, como eixo condutor, os fundamentos teóricos das Representações Sociais ${ }^{(2)}$. Adota, também, como suporte complementar, para interpretação do fenômeno estudado, os estudos da Psicopatologia do Trabalho e Psicodinâmica do Trabalho ${ }^{(1,3-4)}$, cujos constructos da psicanálise, integrados a uma visão dialética, são utilizados para apreensão dos fenômenos subjetivos das vivências das enfermeiras, numa perspectiva sócio-histórica da organização do trabalho. Ainda como suporte complementar, utiliza os estudos sobre trabalho feminino e saúde ${ }^{(5)}$.

Considerando a subjetividade do objeto de estudo, esta pesquisa utiliza a entrevista semi-estruturada, por entender que a mesma possibilita uma investigação mais ampla do tema em pauta. Por meio das entrevistas, na percepção de um grupo de enfermeiras buscam-se, as imagens e representações utilizadas por elas para expressar as vivências do trabalho/sofrimento/prazer - a saúde mental no trabalho da enfermagem. A partir das perspectivas de cada uma, enquanto pessoas dotadas de subjetividade, de horizontes conceituais próprios, de intenções particulares e coletivas e de visão de mundo, busca-se a conexão entre trabalho na enfermagem e saúde mental.

As questões norteadoras, configuradas nas entrevistas, são: 0 que significa, para você, trabalhar como enfermeira? Seu trabalho Ihe dá prazer? O que significa, para você, esse prazer? Seu trabalho lhe causa sofrimento? O que significa, para você, esse sofrimento? 0 que você faz para superar esse sofrimento? 
As enfermeiras, sujeitos desta pesquisa, foram orientadas e concordaram em participar por meio do consentimento livre e esclarecido. As entrevistas foram gravadas com aquiescência das participantes, assegurando-lhes 0 sigilo e 0 anonimato das falas. Depois de transcritas, as entrevistas foram analisadas buscando-se desvendar o discurso enquanto uma estrutura de representação que conduz à emergência da subjetividade como instrumento de conhecimento. Dos depoimentos registrados, foram assinaladas as expressões que evidenciaram as vivências referentes à luta e ao enfrentamento cotidiano e foram analisadas com base nas representações identificadas. Foram codificados os dados mais relevantes apresentados nas falas, objetivando o núcleo de compreensão do texto. Em seguida, foram feitos recortes do texto em unidades de significação que constituíram dimensões figurativas sobre o tema, definidas a partir do objeto deste estudo.

O "locus" sobre o qual esta investigação se desenvolveu foi constituído por dois hospitais gerais de grande porte, da rede pública, de uma cidade do nordeste brasileiro.

Os sujeitos desta pesquisa foram 23 (vinte três) trabalhadoras enfermeiras que exercem suas atividades nos hospitais, campos desta investigação - um grupo intencionalmente constituído a partir da sua inserção no mundo do trabalho. A participação dessas enfermeiras na pesquisa foi voluntária, sendo informadas, por meio do consentimento livre e esclarecido, de sua inteira liberdade de conceder ou não as entrevistas solicitadas.

\section{INSTRUMENTAÇÃO TEÓRICA}

As Representações Sociais constituem-se numa forma particular de adquirir conhecimentos, comunicar o conhecimento que tenha sido adquirido e torná-lo mais ordenado a partir das percepções que produzem o mundo; constituem-se numa forma de conhecimento prático, socialmente construído para dar sentido à realidade da vida cotidiana. Esse saber tem uma função dupla, ou seja, ao tempo em que ele estabelece uma ordem que permite aos indivíduos orientaremse e dominarem o seu mundo material e social, ele, também, possibilita a comunicação entre os membros de um determinado grupo $^{(2)}$. É um conhecimento revestido de criatividade, não sendo, portanto, uma simples cópia de uma realidade preexistente, nem, tampouco, produto da imaginação. Sua construção se dá na interface objetivo-subjetivo, coletivo-individual ${ }^{(6)}$.

0 estudo das representações sociais diz respeito àquilo que os seres humanos pensam. Através das representações sociais, estudam-se indivíduos e grupos não como receptores passivos, mas como sujeitos que pensam de forma autônoma, produzem e comunicam suas idéias no seu meio social, o que influencia, de forma efetiva, a maneira como se desenvolvem suas relações sociais ${ }^{(2)}$. Esses fundamentos constituem importante instrumento de aproximação e compreensão das interações vivenciadas pelas trabalhadoras da enfermagem, fornecendo elementos técnicometodológicos capazes de favorecer uma compreensão da realidade da saúde psíquica no trabalho na enfermagem.

Representação Social significa uma forma de conhecimento específico, orientado para a comunicação e compreensão do mundo em que vivemos; constitui-se num saber prático que é atualizado na ação do sujeito; é o saber do senso comum, cujos conteúdos manifestam a operação de processos generativos e funcionais, socialmente caracterizados, isto é, designa uma forma de pensamento elaborado e compartilhado socialmente, que se manifesta através de imagens, conceitos e categorias, contribuindo para a construção de uma realidade comum a um conjunto social e que possibilita a comunicação( ${ }^{(7)}$.

Nesse entendimento, as representações de enfermeiras sobre a relação trabalho/saúde mental, são fenômenos sociais que, mesmo sendo apreendidos no seu conteúdo cognitivo, devem ser entendidos a partir do seu contexto de produção, ou seja, a inserção da enfermeira no seu trabalho, as funções simbólicas e ideológicas do trabalho feminino e as formas de comunicação que aí circulam.

São dois os processos básicos de construção das representações sociais, a ancoragem e a objetivação. A ancoragem consiste na inserção orgânica daquilo que é estranho no pensamento já construído; o desconhecido é ancorado nas representações já existentes, tornando o estranho familiar - processo de domesticação da novidade na realidade social vivida. A objetivação, operação formadora de imagens, diz respeito à cristalização de uma representação, isto é, a constituição formal do conhecimento. Noções abstratas são transformadas em algo concreto, tornando-se tão vividos que seu conteúdo interno assume o caráter de uma realidade externa ${ }^{(2)}$. Vale salientar que, apesar de as representações se cristalizarem, elas não são imutáveis, pois, por meio de influências sociais, elas sofrem modificações - são estruturadas. Elas são, também, estruturantes, uma vez que dão significado à realidade $\mathrm{e}$ incorporam, numa rede de significados, aquilo que é estranho ${ }^{(6)}$. A ancoragem é a interpretação do sujeito sobre uma dada realidade; $\mathrm{e}$ a objetivação é a simbolização. A objetivação e a ancoragem são referidas como formas específicas em que as representações sociais estabelecem mediações, trazendo a produção simbólica para um nível quase material, dando conta da concreticidade das representações sociais na vida social. Objetivar é, portanto, condensar significados diferentes; ao assim fazer, os sujeitos sociais ancoram o desconhecido em uma realidade conhecida e institucionalizada ${ }^{(7)}$. 
SAÚDE MENTAL E TRABALHO NA ENFERMAGEM

As representações das enfermeiras sobre seu trabalho e sobre a relação desse trabalho com a sua saúde mental, evidenciam um conjunto de significados e significações, que retratam as concepções sobre si mesmas, em determinada realidade organizacional. Essas representações convergem para um conjunto de idéias elaboradas a partir das relações estabelecidas por essas profissionais com seu espaço de trabalho, referindo-se ao nível de realização e necessidades, aos anseios, desejos, inquietações e expectativas, estando associadas às representações elaboradas e circulantes no conjunto de atividades e relações desenvolvidas no trabalho.

As representações advindas das entrevistas do presente estudo constituíram três dimensões figurativas relacionadas ao objeto do presente estudo, ou seja, "saúde mental e trabalho na enfermagem como expressão da realidade individual e coletiva da enfermeira", "0 sofrimento patogênico e o sofrimento criativo no trabalho da enfermagem" e "a enfermeira como produto e produtora da saúde mental no trabalho".

Saúde mental e trabalho na enfermagem como expressão da realidade individual e coletiva da enfermeira

Por meio das falas deste estudo, verifica-se que o trabalho da enfermeira, por sua natureza e conteúdo, envolve a esfera psicoafetiva dessas profissionais - esforços mentais, demanda de maior esforço para concentração da atenção, duração da exposição e intensidade do ritmo de trabalho. Nessa realidade, articulam-se elementos afetivos, mentais e sociais que integram a cognição, a linguagem e a comunicação das relações sociais que afetam as representações sociais e a realidade material, social e ideativa sobre a qual elas intervêm ${ }^{(2)}$. Isso fica ilustrado nos fragmentos das falas a seguir apresentados:

- Gosto muito do meu trabalho, mas tem dias que fico tensa com tanta aparelhagem na minha frente e porque, se esses aparelhos não funcionarem a contento, a vida do cliente fica ameaçada. Muitas vezes você está cansada, saindo de outro plantão...aí uma distração qualquer pode ser fatal. Além do mais, você não tem o controle sobre o processo de trabalho, pois o ritmo é definido pela instituição, pelas normas de uso dos equipamentos, pela demanda; não é o seu ritmo que é respeitado, mas o ritmo necessário à organização. Como você vê, o cotidiano do nosso trabalho é ameaçador para nossas emoções, para nosso psíquico. Como ficam nossas emoções quando saímos do trabalho e voltamos para casa, onde continuamos com nossas tarefas domésticas? Como ficam nossas relações com nossos familiares? E no final da semana, no final do mês, como estamos? Tenho pensado muito nisto, mas não posso prescindir do meu trabalho; por outro lado, também, não posso deixar que ele acabe comigo e com a minha família. (E 7)

- Fico o dia todo com a mente, os braços e as pernas ocupadas; quando termino o meu plantão, minha cabeça não comanda mais o meu corpo que só pede cama; mas, procuro vencer o cansaço, pois tenho a outra jornada de trabalho como mãe, esposa e dona de casa. Isto sem falar que ser enfermeira, significa atender questões de saúde de outros familiares - irmãos, sobrinhos, tios, etc...Não tem saúde mental que agüente. (E 12)

- As minhas condições de trabalho, as características do meu trabalho quase sempre se estendem à minha vida doméstica e vice-versa. Quando eu estou bem em casa, eu estou bem no trabalho; quando estou bem no trabalho, estou bem em casa; mas quando estou mal no trabalho...coitados dos meus filhos, do meu companheiro, isto sem falar na minha ausência em casa à noite. (E 21)

Confirma-se aí a questão do desdobramento da jornada de trabalho feminino que começa em casa, continua na empresa e termina (quando termina) em casa, novamente, em função das tarefas domésticas que não têm descanso semanal, nem férias remuneradas - tarefas que não ajudam a elevar a auto-estima das mulheres trabalhadoras - podendo levar à fadiga crônica e à exaustão física e mental. A dupla ou tripla jornada de trabalho feminina significa, para as enfermeiras estudadas, uma sobrecarga e um desgaste que impõem um permanente esforço de articulação das esferas doméstica e profissional que implicam sérias repercussões sobre a saúde da mulher ${ }^{(5)}$.

A vida familiar e a vida no trabalho manifestam papéis de enfermeiras/mulheres/mães que não conseguem separar, nelas próprias, o mundo do lar e o do trabalho. De fato, o trabalho da enfermeira implica processos construídos não só no interior do espaço do trabalho mas, também, em processos que se desenvolvem fora desse espaço, isto é, no espaço doméstico, familiar ou social da enfermeira.

Na fala a seguir, observa-se a exigência de disponibilidade e supremacia da vida profissional no trabalho sobre a vida familiar: - Procuro fazer meu trabalho com competência. Procuro estar disponível. Quando tenho que dar horário dobrado, faço tudo para não demonstrar os problemas que essas horas complementares vão acarretar para mim em relação à minha família. (E 1)

Verifica-se, aí, uma tensão entre os dois pólos, entre dois mundos, podendo levar a conflitos que, instalados, tendem a configurar a vida profissional como uma privação na vida da mulher. A incompatibilidade entre a vida do trabalho e a da família traduz-se, muitas vezes, em insatisfações e frustrações, pois a mulher se debate com a dúvida sobre o que é mais importante para a sua vida, tendendo a privilegiar a casa e a família.

Em outra fala, percebe-se que as enfermeiras desse estudo evitam o sofrimento quando conseguem estar disponiveis para os 
dois pólos (família e trabalho) simultaneamente. Isso, entretanto, pode levar as enfermeiras a conflitos com grande carga afetiva:

- Consigo equilibrar meu trabalho com minha casa, mas isso custa caro à minha saúde; faço um esforço sobre-humano para compatibilizar os dois. (E 5)

Outras enfermeiras, ainda, consideram que os papéis de enfermeiras/mulheres/mães são incompatíveis porque a sociedade assim os definiu, isto é, são socialmente construídos, conforme ilustrado abaixo:

- O nosso trabalho é muito espinhoso e sem recompensas, além do mais convivemos diariamente com a dor e com a morte, o que é muito desgastante para nossas emoções. $E$, ainda, o que é pior, pensam que a enfermeira é desprovida de emoções, achando que a mesma deve estar sempre "feliz", "bem humorada", "pronta para ouvir", "pronta para servir", "ser pontual e assidua", enfim, pensam que a enfermeira é um ser extraterrestre, uma super mulher maravilha que não tem nenhum problema pessoal e que vive num mar de rosas. Nossos chefes pensam que não somos seres humanos. (E 7) - Apesar dos avanços da minha profissão, ainda nos falta uma certa autonomia, um maior controle nas formas de organização e nas condições do nosso trabalho e isto me deixa um tanto desencantada. Tem horas que eu perco até a força e a vontade de lutar para ampliar o nosso espaço. (E 17)

- O meu trabalho me dá não apenas satisfação financeira; ele também me dá alegria, preenche meu tempo, minha vida, minhas emoções. As minhas amizades são fruto do meu trabalho. Não consigo ver minha vida sem o meu trabalho. Algumas situações no ambiente de trabalho nos causam insatisfações, mas não chegam a causar prejuízos; outras a gente consegue passar por cima, e outras, ainda, eu procuro vencê-las, enfrentando a causa da insatisfação. $O$ fato de estarmos, em algumas situações, sem o domínio ou o controle da situação, nos incomoda um pouco, mas tenho a clareza de que isso não é um problema individual , meu ou de outra colega qualquer, mas, sim, um problema coletivo da categoria. Por isso mesmo, é que procuro me engajar nas lutas em defesa da categoria, pois só por meio do nosso nivel de organização é que poderemos conquistar melhores formas de organização e condições de trabalho na enfermagem. (E 9)

As representações das enfermeiras sobre o seu trabalho, nesta investigação, expressam-lhes a realidade individual e coletiva, referindo-se, portanto, às idéias veiculadas na sua realidade de trabalho, tendo significados próprios e valores pessoais atribuídos a essa realidade. Elas estão acrescidas de múltiplas percepções e associações feitas pelas enfermeiras no decorrer da sua existência individual e coletiva.

Verifica-se, assim, que a realidade social representada por essas enfermeiras, desempenha um papel constitutivo na gênese das representações da atividade simbólica da saúde mental no trabalho e dela própria individualmente, evidenciando que as representações vão além do trabalho individual do psiquismo e emergem como um fenômeno aderente ao tecido social.

O sofrimento patogênico e o sofrimento criativo no trabalho da enfermagem

As enfermeiras estudadas informam que, em sua luta contra o sofrimento, constroem estratégias defensivas que são, em geral, favoráveis, ao mesmo tempo, à organização e à sua saúde (sofrimento criativo). Nas suas falas, percebe-se que o sofrimento patogênico existe no trabalho quando seu contexto gera incômodo, esforço e sofrimento demasiados, sobre o qual (o contexto) as enfermeiras não têm o controle; quando não há possibilidade de acomodação à organização do trabalho, instala-se a relação conflitual do aparelho psíquico com o trabalho. Abre-se, então, o domínio do sofrimento; a energia pulsional, não encontrando formas de drenagem no exercício do trabalho, acumula-se no aparelho psíquico, ocasionando sentimentos de tensão e sofrimento. Na luta contra esse sofrimento, as enfermeiras constroem mecanismos desfavoráveis à organização e à sua saúde (sofrimento patogênico). A essência das falas dessa dimensão está corroborada nos estudos da Psicopatologia e Psicodinâmica do Trabalho ${ }^{(1,3-4)}$ e podem ser ilustradas nos fragmentos, a seguir apresentados:

- O repouso inadequado me causa um desequilibrio no meu estado emocional. Quando começo a ficar irritada com meus filhos, com meu marido e com a empregada é porque estou precisando descansar... aí eu tiro uns dias de folga, descanso e volto ao meu trabalho de uma forma renovada, com mais disposição. É preciso de vez em quando buscar uma renovação seja através de descanso, seja através de um curso para se atualizar e para renovar as idéias, para tomar fôlego, senão...já viu, não é? (E 4)

- Sofro muito quando me sinto impotente para fazer alguma coisa por um paciente em estado terminal; o sofrimento alheio me incomoda, principalmente quando estou impotente para resolver determinada situação; chego até a ter dor de cabeça e insônia, algumas vezes. 0 trabalho na enfermagem tem esse lado negativo que me causa sofrimento. Não consigo vencer esse meu sofrimento e, tendo conhecimento dessa minha dificuldade evito cuidar de pacientes terminais; quando não posso me furtar desse tipo de cuidado, eu passo o resto do dia improdutiva no meu trabalho. (E 10)

Percebe-se, que entre o trabalho e o funcionamento psíquico das profissionais estudadas, interpõem-se estratégias defensivas, isto é, defesas construídas pelo individual (repressão das pulsões) e pelo coletivo das enfermeiras (ideologias defensivas de profissão - construídas contra as pressões organizacionais do trabalho).

- Quando tem algo me incomodando, eu procuro não pensar; eu reprimo esse ou aquele fato que me incomoda e começo a pensar nas coisas boas que já me aconteceram ou que podem acontecer; fujo pela fantasia; sei que 
é uma forma de fugir do problema, mas sei, também, que é a forma que tenho para me proteger contra o mal-estar psíquico; não sei agir de outra forma; na minha educação, na minha formação, não aprendi a fazer o enfrentamento.(E 8)

- No dia em que eu estou muito aborrecida com meu trabalho, cansada ou desgastada, eu vou andar na praia, vou nadar na piscina ou vou fazer uma sauna. Ai eu me sinto outra e até esqueço as adversidades do meu trabalho naquele dia. (E 11)

Essas falas encontram suporte no chamado conhecimento latente acumulado, resultado do viver e atuar numa determinada realidade ${ }^{(8)}$. Esse conhecimento revela a realidade de um modo diferente da ciência formal, possibilitando organizar e analisar os achados obtidos a partir dela. É uma realidade que desempenha papel constitutivo na gênese das representações, da atividade simbólica da própria enfermeira.

Outro destaque nas falas é a questão da falta de controle sobre o contexto do trabalho. Para as enfermeiras, o controle sobre o contexto do seu trabalho implica o conhecimento sobre a tarefa realizada, na possibilidade de interferir e mudar o seu trabalho de acordo com suas necessidades, além de dizer respeito ao quanto, quando e como é possível suportar as estimulações do contexto do seu trabalho. Entende-se, nas falas, que, quando inexistem esses requisitos que sustentam o controle, ocorre a ruptura do equilíbrio, sendo ultrapassado o limite subjetivo, surgindo problemas de saúde. - A convivência com paciente agonizante é muito dolorosa. A perspectiva de assistir à morte do outro é uma experiência traumatizante que me deixa impotente e me faz sofrer. Quando assisto a uma mãe deixando seus filhos, começo a sofrer só em pensar que, um dia, também, deixarei os meus. A convivência com a morte, com o sofrimento alheio, tem o poder de abalar minhas emoções, de me fazer sofrer. Sei que isso pode ser uma fraqueza de minha parte, mas sei, também, que as características do meu trabalho favorecem esse meu sofrimento. (E 9)

Percebe-se, através desse depoimento, o trabalho como extensão do cotidiano da mulher com o cuidado das crianças e da família e de como o convívio com o sofrimento do trabalho lhe reporta ao seu papel de mulher e mãe.

O caráter simbólico e imaginativo do saber das enfermeiras sobre o sofrimento criativo e sofrimento patogênico traz à tona a dimensão dos afetos, pois essas mulheres, enquanto sujeitos sociais, empenham-se em entender e dar sentido ao mundo do seu trabalho, fazendo-o com emoção.

A enfermeira como produto e produtora da saúde mental no trabalho

Fica evidenciado, no discurso das enfermeiras deste estudo, que elas não apenas reproduzem o conhecimento sobre a relação trabalho/saúde mental, mas reconstroem esse conhecimento, retocando-o e modificando-0.

Constata-se que a representação da saúde mental no trabalho é uma construção da enfermeira enquanto um sujeito social que não é apenas produto de determinações sociais, nem produto independente, pois suas representações são sempre construções contextualizadas resultantes das condições em que surgem e circulam. As representações das enfermeiras, neste estudo, por um lado, são construídas e, por outro, formam a vida social das mesmas, orientando suas ações no cotidiano do seu trabalho.

0 posicionamento dessas enfermeiras sobre a relação do seu trabalho com a sua saúde mental foge tanto ao determinismo social - onde ela é produto da sociedade - quanto ao voluntarismo puro que vê a enfermeira como livre agente, o que traz para o centro da discussão a questão das emoções. As representações não são meras expressões cognitivas, mas são, também, permeadas pelas emoções, conforme as ilustrações abaixo:

- Me conforta a certeza de que existem aspectos positivos no meu trabalho, e esses aspectos me fazem muito bem; alguns até me realizam como mulher e como profissional.(E 6)

- O meu trabalho me dá muitas alegrias, satisfações... mas, também me dá muitos aborrecimentos. Mas a minha vida particular, também me dá alegrias e nostalgias. Tudo na vida é assim, com altos e baixos; eu subo e desço, conforme o momento, conforme a situação; e assim vou vivendo minha vida, minha profissão, meu trabalho, meu mundo. (E 3)

- Eu trabalho como uma danada. Tenho dois empregos para poder sobreviver com meus dois filhos. Mas, nem por isso eu me entrego. Procuro equacionar o meu tempo, senão eu fico louca... Teve um dia que minha cabeça fervia tanto...tanto...que eu precisei sair um pouco, tomar uma cervejinha, um banho de mar com umas amigas para relaxar. É preciso amar a si próprio para poder amar os outros e trabalhar em paz, com o juízo no lugar. (E13)

- Eu preciso do meu trabalho, mas preciso também da minha saúde para trabalhar, por isso eu não me permito ficar esticada. Quero o meu trabalho, porém não quero adoecer. Procuro evitar o sofrimento fazendo o meu trabalho da melhor maneira possível, buscando promoção, mas sem procurar prejudicar ninguém. Me preservo, também, evitando levar problemas do trabalho para minha casa. Não faço da minha casa uma extensão do meu trabalho; procuro separar as coisas. Por outro lado, também, eu procuro resolver os problemas do meu trabalho no próprio espaço do trabalho; se tem alguma coisa me incomodando no meu trabalho, aqui mesmo eu resolvo; vou até minha chefe, converso, esclareço as dúvidas e reivindico minhas expectativas. Esse negócio de dizer que enfermeira é submissa, não tem nada a ver comigo. (E 22)

- Procuro me adaptar ao serviço que me é determinado para não sofrer. (E 10)

- Procuro redesenhar, reprogramar minhas atividades no trabalho, de tal forma que elas não interfiram na minha saúde psíquica. Estou sempre fazendo negociações com minha chefia e com meu companheiro. (E 15) 
Observa-se, nesses fragmentos de falas, que a compreensão do vivido no trabalho produz o sentido, e esse sentido produz o sujeito - a enfermeira torna-se produtora da sua própria história. Nessas falas, percebe-se que as adversidades das condições de trabalho e as emoções em tais condições são fatores que determinam representações sociais especificas, onde o trabalho assume papel na conformação da identidade e na sua saúde mental, ou seja, possui uma dinâmica capaz de conformar a identidade e o modo de viver da enfermeira, de acordo com a atividade/função que ela exerce.

Cada enfermeira busca suas saídas e convivências com seu sofrimento e as formas de descarregar sua energia pulsional. Observam-se formas de resistência ao sofrimento e estratégias defensivas mobilizadas contra a possibilidade de adoecimento. A não descarga da energia pulsional e, conseqüentemente, o acúmulo da carga psíquica, somados à impossibilidade ou à insuficiência das descargas pelas vias motora e visceral, vão conduzir o indivíduo a enveredar na via mental, por um processo de construção de neurose. Essa carga psíquica se constitui na insatisfação resultante de um conteúdo ergonômico inadaptado à estrutura da personalidade. Por outro lado, se a energia pulsional do trabalho se descarrega regularmente, 0 trabalho torna-se equilibrante e não fatigante ${ }^{(4)}$. Quando a enfermeira, de acordo com as características organizacionais do seu trabalho, consegue agir sobre 0 acontecimento, evitando a tensão que ameaça e não ficando impotente face às fontes de agressão psíquica (agressão psíquica da morte, da sobrecarga e do desgaste) geradas pelo trabalho, ela pode descarregar a energia pulsional. Essa descarga de energia pode ser por via psíquica ou por via motora. Essa situação está ilustrada nas falas abaixo:

- Quando tem algo me incomodando, eu procuro não pensar, eu reprimo esse ou aquele fato que me incomoda e começo a pensar nas coisas boas que já me aconteceram ou que podem me acontecer; fujo pela fantasia; sei que é uma forma de fugir do, problema, mas sei, também, que é a forma que tenho para me proteger contra o mal-estar psíquico; não sei fazer de outra forma; na minha educação, na minha formação não aprendi a fazer o enfrentamento, então eu me defendo pela fuga através da fantasia. (E 2) - Na minha vida eu me defendo como posso. Quando pequena, aprendi que é necessário ter tempo para tudo, é preciso encontrar alegria nas mínimas coisas da vida, senão a corda estica e...já viu...,no dia em que minha vida particular e minha vida no trabalho não me permitirem drenar minhas tensões, aí eu vou estar com minhas capacidades defensivas ultrapassadas e não vou conseguir manter minha saúde, principalmente minha saúde mental. ( $\mathrm{E}$ 5)

As falas nos mostram, também, que, apesar do insuficiente poder para interferir no contexto do seu trabalho, as enfermeiras entrevistadas evitam, continuamente, ultrapassar o limite subjetivo, prevenindo a ruptura do equilibrio, através de ações adaptativas que modificam o trabalho planejado sem, no entanto, replanejá-lo, o que, por sua vez, implica ter que enfrentar os mesmos problemas repetidas vezes, diariamente. As ações adaptativas evidenciadas mostram a existência de uma organização do trabalho, com procedimentos previstos, e uma organização que de fato ocorre. Essas ações adaptativas, ao modificarem o trabalho planejado, interferem na qualidade do produto (no caso, o serviço prestado), podendo não só melhorá-lo, mas, também, comprometê-lo - sofrimento criativo/ sofrimento patogênico ${ }^{(1,3-4)}$. Tais ações são coletivamente construídas, mas, individualmente praticadas, uma vez que estão referenciadas ao limite de cada trabalhadora. Sua construção se dá, na prática, tanto através da vivência direta, como através da observação e da troca de informações entre as companheiras de trabalho. Há quem considere essas ações adaptativas, como inadequações do(a) trabalhador(a) ao trabalho (sendo indesejáveis à produção) e não como jeito possível de continuar trabalhando nos contextos existentes $^{(9)}$. Entretanto, vale salientar que são essas ações adaptativas que, algumas vezes, evitam problemas da esfera psíquica dos trabalhadores. Nesse sentido, observa-se que os transtornos psíquicos se apresentam quando as exigências do meio e do trabalho ultrapassam a capacidade de adaptação do sujeito, ou suas possibilidades defensivas ${ }^{(10)}$.

As ações adaptativas desenham uma forma de resistência, através do sofrimento patogênico e do sofrimento criativo, mobilizadas para manter a saúde mental. As enfermeiras elaboram estratégias para enfrentar mentalmente as adversidades do trabalho. Nesse sentido, a normalidade aparece como um equilíbrio psíquico entre constrangimento do trabalho desestabilizante ou patogênico e defesas psíquicas. Esse equilibrio seria o resultado de uma regulação que requer estratégias defensivas elaboradas pelos trabalhadores - no caso do presente estudo, pelas enfermeiras. As ações adaptativas refletem a luta das trabalhadoras para manter o equilíbrio, a estabilidade que é mesclada pelo sofrimento que pode ser visto como o espaço de luta entre o bem-estar e a loucura. Essa luta, destarte, tem relação com a organização da personalidade, da história e do passado de cada uma das entrevistadas.

A complexidade dessas ações aponta para a dialética da construção dos sistemas defensivos. O mesmo objeto que faz sofrer, faz também resistir. A organização do trabalho desencadeia, portanto, mecanismos psíquicos adaptativos.

\section{CONCLUSÕES}

Através dessa investigação, observa-se que as representações das enfermeiras entrevistadas, revelam visões 
multifacetadas do trabalho, possibilitando 0 avanço nas abstrações e compreensão acerca da relação saúde mental e trabalho da enfermagem. Pode-se perceber que essas enfermeiras tornam real um esquema conceitual; elas reabsorvem os significados da relação saúde mental e trabalho na enfermagem (como trabalho feminino), materializando esses significados e transplantando-os para o nível do concreto, o que era apenas uma inferência ou símbolo.

Identificam-se representações carregadas de sentimentos que marcam 0 ideário das enfermeiras e que são decorrentes de outras representações anteriormente elaboradas, caracterizando um processo recorrente, o que permite visualizar o trabalho na enfermagem como fator de sofrimento criativo ou sofrimento patogênico.

A construção e modificações das representações das enfermeiras entrevistadas, sobre a saúde mental no seu trabalho estão situadas nos contextos sociais em que ocorrem e norteiam suas práticas, suas relações interpessoais e suas relações com os objetos de trabalho. Enfim, as representações dessas enfermeiras sobre a relação saúde mental e trabalho na enfermagem são a expressão simbólica de um fenômeno psíquico no qual o seu desenvolvimento está ligado a uma situação organizacional ou profissional.

As representações aqui estudadas não são uma realidade abstraída de um mundo social. Elas se constroem e tomam forma por meio de um processo de assimilação da realidade das enfermeiras, onde se integram suas experiências, seus valores, as informações que circulam no seu meio sobre saúde mental e sobre as relações que se estabelecem entre as pessoas do seu meio; elas dirigem e orientam o comportamento dessas profissionais, ainda que não sejam percebidas como formações ideológicas. As representações sobre saúde mental e trabalho na enfermagem formam-se, pois, no seu cotidiano e constituem-se em estruturas simbólicas que se originam tanto na capacidade criativa do psiquismo dessas enfermeiras como nas fronteiras que 0 trabalho na enfermagem lhes impõe.

As enfermeiras, aqui estudadas, são portadoras de um conhecimento gerado no seu dia-a-dia de trabalho e este deve ser privilegiado, devendo ser o ponto de partida da luta pela saúde mental dessas profissionais nos seus locais de trabalho. Suas representações trazem a marca do individual e do coletivo organizacional, devendo ser entendidas a partir do seu contexto de produção, isto é, a partir não só das funções simbólicas e ideológicas a que servem, mas, também, das formas de comunicação onde circulam. Tal fato deve permitir a tomada de consciência de que as variações na relação saúde mental e trabalho na enfermagem não são características próprias de cada enfermeira, mas de situações sociais em que elas se encontram tanto no trabalho, como na família e em situações sociais mais amplas.

\section{REFERÊNCIAS BIBLIOGRÁFICAS}

1. Dejours C. Uma nova visão do sofrimento humano nas organizações. In: Chanlat JF, organizador. O indivíduo na organização: dimensões esquecidas. São Paulo (SP): Atlas; 1993. p.149-74.

2. Moscovici S. A representação social da psicanálise. Rio de Janeiro (RJ): Zahar; 1978.

3. Dejours C. A loucura do trabalho. São Paulo (SP): Cortez-Oboré; 1992.

4. Dejours C. A carga psíquica do trabalho. In: Dejours C. et al. Psicodinâmica do trabalho. São Paulo (SP): Atlas; 1994.

5. Marañano M. Mujer, trabajo, salud. Madrid: Editorial Trotta; 1992.

6. Spink MJ. $O$ conceito de representação social na abordagem psicossocial. Cad Saúde Pública 1993 jul./set; 9 (3): 300-8.
7. Jodelet D. Les representations sociales. Paris: Presses Universitaires de France; 1989.

8. Laurell AC, Noriega M. Processo de produção e saúde: trabalho e desgaste operário. São Paulo (SP): HUCITEC; 1989.

9. Sato L. O conhecimento do trabalhador e a teoria das representações sociais. In Codo W, Sampaio JJC, organizadores. Sofrimento psíquico nas organizações: saúde mental e trabalho. Petrópolis (RJ): Vozes; 1995. p.48-57.

10. Carvalho RA. Saúde mental e trabalho: um novo (velho) campo para a questão da subjetividade. In: Codo W, Sampaio JJC, organizadores. Sofrimento psíquico nas organizações: saúde mental e trabalho. Petrópolis: Vozes; 1995. p.58-64. 